OPEN ACCESS

Edited by: Antonella Di Pizio, Technical University of Munich,

Germany

Reviewed by:

Franziska Marie Heydenreich, Stanford University, United States

Mercedes Alfonso-Prieto, Helmholtz Association of German Research Centres (HZ), Germany Christoph Klenk

University of Zurich, Switzerland

${ }^{*}$ Correspondence: Graham Ladds grl30@cam.ac.uk David R. Poyner

D.R.Poyner@aston.ac.uk

${ }^{\dagger}$ Present address: Kerry Barkan,

Molecular Pharmacology, Sosei Heptares,

Cambridge, United Kingdom

Nathan J. Robertson, MiroBio, Oxford, United Kingdom Ali Jazayeri,

OMass Therapeutics, Oxford, United Kingdom

Specialty section:

This article was submitted to Cellular Endocrinology,

a section of the journal

Frontiers in Endocrinology

Received: 11 October 2021 Accepted: 15 December 2021 Published: 13 January 2022

Citation:

Winfield I, Barkan K, Routledge S, Robertson NJ, Harris M, Jazayeri A, Simms J, Reynolds CA, Poyner DR and Ladds G (2022) The Role of ICL1 and $\mathrm{H} 8$ in Class B1 GPCRs: Implications for Receptor Activation.

Front. Endocrinol. 12:792912. doi: 10.3389/fendo.2021.792912

\section{The Role of ICL1 and H8 in Class B1 GPCRs; Implications for Receptor Activation}

\author{
lan Winfield ${ }^{1}$, Kerry Barkan ${ }^{1 \dagger}$, Sarah Routledge ${ }^{1,2}$, Nathan J. Robertson ${ }^{3+}$, \\ Matthew Harris ${ }^{1}$, Ali Jazayeri ${ }^{3+}$, John Simms ${ }^{2}$, Christopher A. Reynolds ${ }^{4}$, \\ David R. Poyner ${ }^{2 *}$ and Graham Ladds ${ }^{1 *}$

\begin{abstract}
${ }^{1}$ Department of Pharmacology, University of Cambridge, Cambridge, United Kingdom, ${ }^{2}$ School of Life and Health Sciences, Aston University, Birmingham, United Kingdom, ${ }^{3}$ Sosei Heptares, Cambridge, United Kingdom, ${ }^{4}$ Centre of Sports Health and Life Sciences, Coventry University, Coventry, United Kingdom
\end{abstract}

The first intracellular loop (ICL1) of G protein-coupled receptors (GPCRs) has received little attention, although there is evidence that, with the $8^{\text {th }}$ helix $(\mathrm{H} 8)$, it is involved in early conformational changes following receptor activation as well as contacting the $\mathrm{G}$ protein $\beta$ subunit. In class B1 GPCRs, the distal part of ICL1 contains a conserved $\mathrm{R}^{12.48} \mathrm{KLRCXR^{2.46b }}$ motif that extends into the base of the second transmembrane helix; this is weakly conserved as a $[R / H]^{12.48} \mathrm{KL}[\mathrm{R} / \mathrm{H}]$ motif in class A GPCRs. In the current study, the role of ICL1 and H8 in signaling through CAMP, ${ }_{i} \mathrm{Ca}^{2+}$ and ERK1/2 has been examined in two class B1 GPCRs, using mutagenesis and molecular dynamics. Mutations throughout ICL1 can either enhance or disrupt CAMP production by CGRP at the CGRP receptor. Alanine mutagenesis identified subtle differences with regard elevation of ${ }_{i} \mathrm{Ca}^{2+}$, with the distal end of the loop being particularly sensitive. ERK $1 / 2$ activation displayed little sensitivity to ICL1 mutation. A broadly similar pattern was observed with the glucagon receptor, although there were differences in significance of individual residues. Extending the study revealed that at the CRF1 receptor, an insertion in ICL1 switched signaling bias between ${ }_{i} \mathrm{Ca}^{2+}$ and $\mathrm{CAMP}$. Molecular dynamics suggested that changes in ICL1 altered the conformation of ICL2 and the H8/TM7 junction (ICL4). For $\mathrm{H} 8$, alanine mutagenesis showed the importance of E390 ${ }^{8.49 \mathrm{~b}}$ for all three signal transduction pathways, for the CGRP receptor, but mutations of other residues largely just altered ERK1/2 activation. Thus, ICL1 may modulate GPCR bias via interactions with ICL2, ICL4 and the Gß subunit.

Keywords: GPCRs, signaling bias, CLR, RAMPs, mutagenesis

\section{INTRODUCTION}

GPCRs form the single largest protein family in the human genome, and they are also the largest single target for therapeutic agents (1). They all share a common architecture based around seven transmembrane helices (TMs), connected by three intracellular and three extracellular loops (ICLs and ECLs), often with an $8^{\text {th }}$ helix (H8), immediately after TM7, lying parallel to the membrane. They 
are divided into several families. The largest and best understood is the class A or rhodopsin-like family. The class B1, or secretin-like family is smaller but is made of receptors for physiologically important peptides such as glucagon, corticotrophin-releasing factor (CRF) and members of the calcitonin gene-related peptide (CGRP) family. There are cryo-electron microscope structures for most of these receptors, showing their structure with Gs or other $G$ proteins (2) and crystal or cryo-EM structures are available for the transmembrane domains of the glucagon, glucagon-like peptide- 1 (GLP-1), CRF type-1 (CRFR1), CGRP and parathyroid type-1 receptors $(3-10)$.

The means by which class A GPCRs recognise G proteins is now understood in detail for a number of receptors (11). There is also growing understanding of GPCR binding to $\beta$-arrestins (12). It has been possible to trace how agonist binding leads to TMs 3 and 6 (and hence ICLs 2 and 3) moving apart, to allow an interaction with the $\mathrm{C}$-terminus of the $\mathrm{G}$ protein. It remains unclear how different receptor-ligand combinations select between individual $G$ proteins or $\beta$-arrestins, although this is key to understanding biased agonism - the phenomenon whereby agonists produce unique signals at receptors (10). The activation of class B1 GPCRs appears to be broadly similar although they have their own unique motifs; thus, residues at the base of TM2 and its junction with ICL1 function in combination with TM 3 to create a $G$ protein-binding pocket (7-10). The individual microswitches used by class A and class B1 are distinct (13). For class B1 GPCRs, it seems that the key to receptor activation is the full engagement of the agonist peptide $\mathrm{N}$-terminus with the TM domain of the GPCR, which initiates changes at the intracellular face of the receptor $(14,15)$. ICL1 has been little studied in either GPCR class. Mutations can disrupt cell surface expression $(16,17)$, indicating the loop is important for structural integrity of the receptor. It is adjacent to ICL2 and in the class A and B1 GPCR structures there is an interaction between it and the proximal region of $\mathrm{H} 8$. The junction between $\mathrm{H} 8$ and TM7 is sometimes known as ICL4. ICL1 has a role in receptor activation, as revealed by mutations in a range of GPCRs from class A and B1 (18-26). Hydrogen-deuterium exchange indicates that different agonists cause distinctive conformational changes in ICL1, similar to those seen at ICL4 (27). Changes in the ICL1-H8 unit precede movement of TMs 5 and 6 in the $\mu$-opioid receptor, showing that they are an early event in GPCR activation $(28,29)$; this may be part of a conserved activation mechanism (30). There is also good evidence for ICL1 playing a role in G protein selectivity through splice variants in class B1 GPCRs (31). The mechanism behind the actions of ICL1 is unclear.

Here we study the role of ICL1-H8 unit in the activation of class B1 GPCRs and in particular, the significance of a motif previously referred to as the $[\mathrm{K} / \mathrm{R}] \mathrm{KLH}$ motif (32) within ICL1 which mediates its interactions with $\mathrm{H} 8$. We have primarily concentrated on the calcitonin receptor-like receptor (CLR), a receptor we have studied $(33,34)$, in association with receptor activity-modifying protein 1 (RAMP1), this forms a receptor for CGRP which can also recognize the related peptide adrenomedullin (AM) (35). We have also examined the glucagon receptor (GCGR) and two splice variants of the CRFR1.

\section{METHODS}

\section{Materials}

Human CGRP and CRF were purchased from Bachem and human glucagon was purchased from Alta Biosciences. All peptides were made to $1 \mathrm{mM}$ stocks in water containing $0.1 \%$ bovine serum albumin (BSA).

\section{Constructs and Site-Directed Mutagenesis of CLR and GCGR}

The CRFR1a and CRFR1b constructs were gifts from Dr. Simon Dowell (GSK, Stevenage, UK). ICL1 mutants of CLR were generated in a pIRES-RAMP1-SNAP-CLR construct in-house by Sosei Heptares and confirmed through Sanger sequencing. ICL1 mutants of the GCGR were generated as for CLR except using a base vector of pcDNA3.1-GCGR-GFP. H8 mutants for CLR and GCGR were generated by using the QuikChange Lightening Site-Directed Mutagenesis Kit (Agilent Technologies) in accordance with the manufacturer's instructions and sequenced in house at Cambridge University. All constructs were of human receptors and RAMP.

\section{Transfection and Cell Culture}

HEK 293T cells (a gift from Professor Colin Taylor) were cultured in DMEM/F12 GlutaMAX supplemented with 10\% fetal bovine serum (FBS), and incubated at 37\% in humidified 95\% air, 5\% $\mathrm{CO}_{2}$. Plasmids were transfected into HEK 293T cells using FuGENE HD according to the manufacturer's instructions using a 1:3 w:v ratio of DNA : FuGENE and cultured for 48 hours prior to assaying.

\section{Quantification of Mutant GPCR Expression}

Cell surface expression of WT and mutant GPCRs was determined in HEK 293 cells via flow cytometry as previously described (36). Briefly, after 48 hours, cells were washed three times in fluorescence activated cell sorting (FACS) buffer (PBS supplemented with $1 \%$ bovine serum albumin (BSA) and $0.03 \%$ sodium azide) before and after 1 hour incubation at room temperature in the dark with appropriate primary antibody; rabbit anti-GCGR (AGR-024, diluted 1:50 (Alomone Labs)) or rabbit anti-SNAP (CAB4255, diluted 1:100, Invitrogen). Cells were then incubated for a further hour at room temperature in the dark in secondary antibody (goat APC-conjugated antirabbit IgG polyclonal antibody, diluted 1:150 (ThermoFisher)). Samples were analysed using a BD Accuri C6 flow cytometer (BD Biosciences) Ex. $\lambda 633 \mathrm{~nm}$ and Em. $\lambda 660 \mathrm{~nm}$. Mean APC intensity indicated the plasma membrane expression of each GPCR. Data were normalized to the mean APC intensity of cells transfected with WT GPCR as 100\% and pcDNA3.1(-) as 0\%.

\section{Measurement of Intracellular cAMP Accumulation}

HEK 293 cells expressing WT or mutant GPCR were assayed for cAMP accumulation as previously described $(33,37)$. cAMP accumulation was measured after 30 minutes stimulation using LANCE $^{\circledR}$ cAMP Detection Kit (Perkin Elmer Life Sciences) on a 
Mithras LB 940 multimode microplate reader (Berthold Technologies). Data were normalized to the maximal level of cAMP accumulation from cells in response to $100 \mu \mathrm{M}$ Forskolin (Sigma) stimulation.

\section{Measurement of Intracellular Calcium Mobilization}

Intracellular calcium mobilisation was measured in transfected HEK 293 cells as previously described using Fluo-4/AM and a Mithras LB 940 multimode microplate reader (33). Data were normalized to the maximal intracellular calcium release in response to $10 \mu \mathrm{M}$ ionomycin.

\section{Measurement of Phospho-ERK $\mathrm{K}_{1 / 2}$ (Thr202/Tyr204)}

HEK 293 cells expressing WT or mutant GPCR were serum starved overnight prior to assaying. Cells were then washed and resuspended in $\mathrm{Ca}^{2+}$ free HBSS and seeded at a density of 35000 cells per well in 384-well white Optiplates (Perkin Elmer). Cells were stimulated with ligand for $5 \mathrm{~min}$, before lysis using the supplied lysis buffer and assayed for ERK1/2 phosphorylation using the phospho-ERK (Thr202/Tyr204) Cellular Assay Kit (Cisbio). Plates were read using a Mithras LB 940 multimode microplate reader and data normalized to the maximal response to $100 \mu \mathrm{M}$ phorbol 12-myristate 13-acetate (PMA, Sigma) (34).

\section{Molecular Dynamics}

PDB structures for the inactive and active conformations of CLR complexed with RAMP1 (PDB codes 7KNT and 6E3Y, respectively) and the GCGR (PDB codes 5EE7 and 6WHC, respectively) were obtained from the PDB. Missing atoms were identified from the PDB header and are available in the original PDB file. They were replaced using MODELLER (38) prior to refinement and scoring using Rosetta (39). To reduce errors introduced by loop modelling, ICL2 was excluded from the MODELLER step. Furthermore, no attempt was made to refine existing regions of secondary structure as are as per the original crystallographic file. The best scoring inactive and active conformations of each receptor type were used for an essential dynamics simulation (40). Each protein was embedded in an equilibrated solvated membrane consisting of 280 POPC lipids. $\mathrm{NaCl}$ was added at a concentration of $150 \mathrm{mM}$, with extra $\mathrm{Cl}^{-}$ions added to the solvent to neutralize the system. Protonation states of charged residues were determined using ProPka (41) prior to the simulation start. Initial equilibration simulations (100 ns) were performed using Gromacs (42) at 310 $\mathrm{K}$ for both the active and inactive receptor states for each receptor family. The equilibrated structures were then used for an essential dynamics simulation. During the essential dynamics simulations, each inactive conformation had a fixed potential applied to the first eight non rotational/translations eigenvectors that increased in fixed increments per step to drive the system from the inactive to the active state. Simulations were performed with fixed increments of $1.2 \times 10^{-6} \mathrm{~nm}$ per each simulation step ( $2 \mathrm{fs}$ ). Each simulation was performed 10 times. The amber-ILDN forcefield was used in all simulations. The simulations were combined into an inactive to active trajectory using the best scoring snapshot, using the Rosetta scoring function at each timestep. The snapshots were not chosen, but are equally spaced conformations that describe the trajectory from inactive to active state. The RMSD between snapshots was approximately 0.01 Angstroms.

\section{Generation of Weblogo's}

GPCR sequences were obtained for 289 human GPCRs in Class A and Class B1 from GPCRdb (https://gpcrdb.org) (43). Sequences were aligned for their ICL1 and H8 using GPCRDB outputs. Weblogo's were then created using free software from] https://weblogo.berkeley.edu using the frequency method where height of each letter represents the frequency of each amino acid.

\section{Data Analysis}

All pharmacological data was analyzed in GraphPad Prism v9.0 (GraphPad Software, San Diego). Data were fitted to obtain concentration-response curves using either the three-parameter logistic equation to obtain values of $\mathrm{E}_{\max }$ and $\mathrm{pEC}_{50}$ or the operational model of agonism (44) as described previously (33, $34)$, to obtain efficacy $(\tau)$ and equilibrium disassociation constant $\left(\mathrm{K}_{\mathrm{A}}\right)$ values. Statistical differences were analysed using one-way ANOVA followed by Dunnett's post-hoc (for comparisons amongst more than two groups). Data was normalized to either activity of Wild Type receptor or relative to a system parameter control; 100 $\mu \mathrm{M}$ forskolin stimulation for cAMP accumulation, $10 \mu \mathrm{M}$ ionomycin for ${ }_{\mathrm{i}} \mathrm{Ca}^{2+}$ mobilizations assays or $10 \mu \mathrm{M}$ phorbol 12 myristate 13-acetate (PMA) for ERK1/2 activation. The means of individual experiments were combined to generate the concentration-response curves displayed in the figures. Having obtain values for $\tau$ and $\mathrm{K}_{\mathrm{A}}$ these were then used to quantify signaling bias as the change in $\log \left(\tau / \mathrm{K}_{\mathrm{A}}\right)$ relative to WT and a reference signaling pathway (ERK1/2) as described previously (34).

\section{RESULTS}

\section{Sequence Conservation Within ICL1 and $\mathrm{H} 8$}

There is a high level of conservation in both ICL1 and H8 in all GPCRs (Figures 1A, B) and especially Class B1 GPCRs (Figures 1C, D). In Class B1 GPCRs only, ICL1 contains an $\mathrm{R}^{12.48} \mathrm{KLRCXR}^{2.46 \mathrm{~b}}$ motif that extends into TM2 (using the Wootten Class B1 numbering, 46); the $\mathrm{C}$ and $\mathrm{R}$ in bold are absolutely conserved. In $\mathrm{H} 8$ there is an $\mathrm{N}^{7.61 \mathrm{~b}} \mathrm{GE}^{8.49 \mathrm{~b}}-\mathrm{V} X \mathrm{xx} X(\mathrm{R} /$ $\mathrm{K}) \mathrm{xW}$ motif where $X$ is hydrophilic, $\mathrm{x}$ is any amino acid and the $\mathrm{E}$ and $\mathrm{V}$ in bold also absolutely conserved (Figure $\mathbf{1}$ and Figure S1). The sequences of ICL1 and H8 motifs are more precise than our initial reports (32); here we only consider human class B1 GPCRs, rather than the full class B sequences (adhesion + secretin families).

\section{Mutational Analysis of the ICL1-H8 Regions of CLR}

To understand the function of ICL1 and H8, we first performed an alanine scan centred on the $\mathrm{R}^{12.48} \mathrm{KLRCxR}$ and $\mathrm{E}^{8.49}$ VXxxX motifs in CLR. The ICL1-H8 motifs (underlined) are represented in the sequences $\mathrm{Y}^{165} \mathrm{FK}^{167 / 12.48 \mathrm{~b}} \mathrm{SLSCQR}^{173 / 2.46 \mathrm{~b}}$ 
ICL1

A

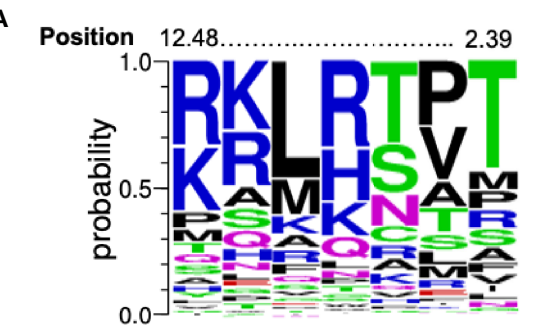

C Position

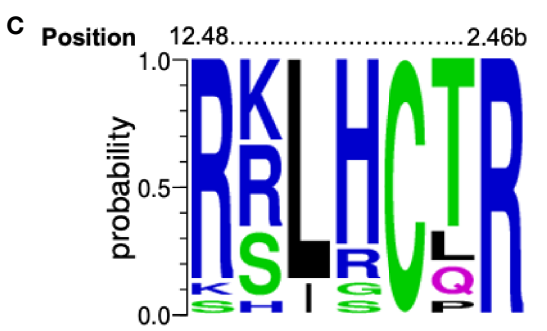

Helix 8

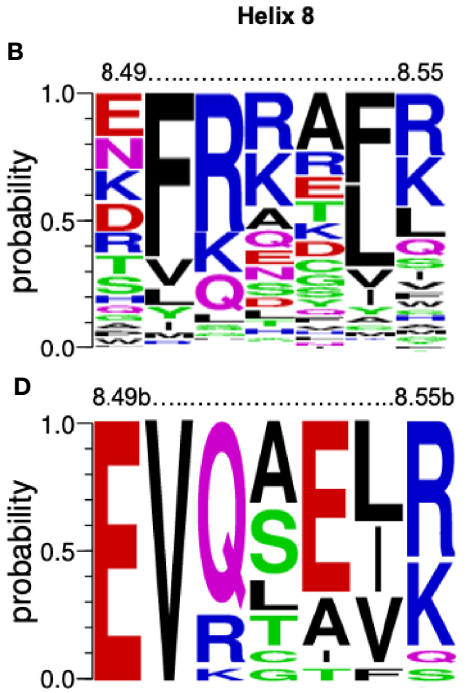

FIGURE 1 | Conservation of the $[K / R] K L[R / H] x x[T / R]$ and EFxxxL motifs. Alignment of the amino acids from 298 human GPCRs (both Class A and B1) for (A) ICL1 and (B) Helix 8 depicted as a weblogo's. Position marked using the Ballesteros-Weinstein numbering systems combined. Alignment of the amino acids from human Class B1 GPCR alone for (C) ICL1 and (D) Helix 8 depicted as a weblogo's (45). Position marked using the Wootten Class B1 numbering, (46). The height of each letter represents the frequency of each amino acid. Amino acids are colour coded to their chemical properties: polar amino acids $(G, S, T, Y, C)$ are green, neutral $(Q, N)$ are magenta, basic $(\mathrm{R}, \mathrm{K}, \mathrm{H})$ are blue, acidic $(\mathrm{D}, \mathrm{E})$ are red, and hydrophobic $(\mathrm{A}, \mathrm{V}, \mathrm{L}, \mathrm{I}, \mathrm{P}, \mathrm{W}, \mathrm{F}, \mathrm{M})$ are black. Figures generated using https://weblogo.berkeley.edu..

and $\underline{\mathrm{N}}^{388 / 7.61 \mathrm{~b}} \mathrm{GE}^{390 / 8.49 \mathrm{~b}} \mathrm{VQAIL}^{395 / 8.54 \mathrm{~b}}$. Almost all mutants were expressed at the cell surface at a third or greater than that of WT (Tables S1, S2 - except I394A), a level which we have previously established that causes little change in agonist potency (47). It should however be noted that we had not checked for effects on efficacy/ $\mathrm{E}_{\max }$ L $169 \mathrm{~A}$ expression was reduced by $72 \%$ and there were also sizeable decreases in expression for E390A, I394A, I397Aand L398A and R399A; the expression of L395A and K167A were reduced by $50 \%$.

When cAMP production was measured, mutation of F166, L169, C171 and Q172 (Table S3A and Figure 2) all reduced CGRP potency or $\mathrm{E}_{\max }$ while $\mathrm{S} 170 \mathrm{~A}$ slightly increased it. For H8 and the base of TM7 there were significant reductions in $\mathrm{pEC}_{50}$ for N388A, E390A (also decreasing $E_{\max }$ ), V391A and W399A (Table S3A).

To provide a comparison of how the ICL1 mutants might influence downstream signaling activity, we renormalised the cAMP accumulations data shown in Figure $\mathbf{2}$ to now account for the maximal level of cAMP accumulation achievable for HEK $293 \mathrm{~T}$ cells (stimulations with the non-selective adenylyl cyclase activator forskolin), (Figure 3A and Table S3B). Beyond cAMP accumulation, CLR can also couple to $G \alpha_{\mathrm{q} / 11}$ to increase intracellular calcium $(33,48)$. When this response is measured, the ICL1 mutants show a somewhat different pattern of activity; whilst L169A and C171A again reduce potency, with S168A there was a decrease in apparent affinity calculated from the operational model (Figure 3B and Table S4). No mutants enhanced coupling. Alanine mutation of the ICL1 appeared to show little overall effect upon CGRP-induced ERK1/2 activation [which was largely independent of Protein Kinase A activation, (34)], with only K167A showing any significant changes; an increase in potency but decrease in $\mathrm{E}_{\max }$ (Figure $3 \mathrm{C}$ and Table S5).

While the changes in potency for cAMP and ${ }_{\mathrm{i}} \mathrm{Ca}^{2+}$ mobilisation appear to suggest changes in signaling bias profiles, to formally confirm this, and to remove potential confounding issues of system bias, we refitted the data in Figure 3 using the operational model of receptor agonism (44). Since the ERK1/2 activation seemed to tolerate mutation at any positions in ICL1, all data was normalised to this parameter (Figure 3D and Tables S3B, S4, S5). This analysis reconfirmed that mutations of residues L169 to Q172 all resulted in a signaling response that was biased away from ${ }_{\mathrm{i}} \mathrm{Ca}^{2+}$ mobilisation and towards cAMP. Moreover, mutations of C171 and Q172 also displayed bias away from cAMP accumulation to a lesser extent than for mobilisation of $\mathrm{Ca}^{2+}$.

We next performed the same array of assays as described for the ICL1 mutants on the CLR H8 mutants. Normalisation of the cAMP accumulation data showed that N388A, E390A, V391A, L395A and W399A all displayed reduced potency (Figure 4A and Table S3B). For ${ }_{i} \mathrm{Ca}^{2+}$ mobilisation, only E390A showed a dramatic reduction in potency (Figure $4 \mathrm{~B}$ and Table S4). Unlike the ICL1 mutants, mutations at every position within the H8 motif changed either potency (with increases for E390A, V391A, and Q392A) or $\mathrm{E}_{\max }$ when ERK1/2 activation was quantified (Figure 4C and Table S5). Analysis using operational parameters confirmed these observations (Figure 4D and Tables S3B, S4, S5). I394A displayed reduced cell surface expression and failed to generate responses for ${ }_{i} \mathrm{Ca}^{2+}$ mobilisation or ERK1/2 activation so was excluded from any analysis although it did show a WT cAMP response, for reasons that are not obvious. Thus, the effects of mutation on ICL1 and 


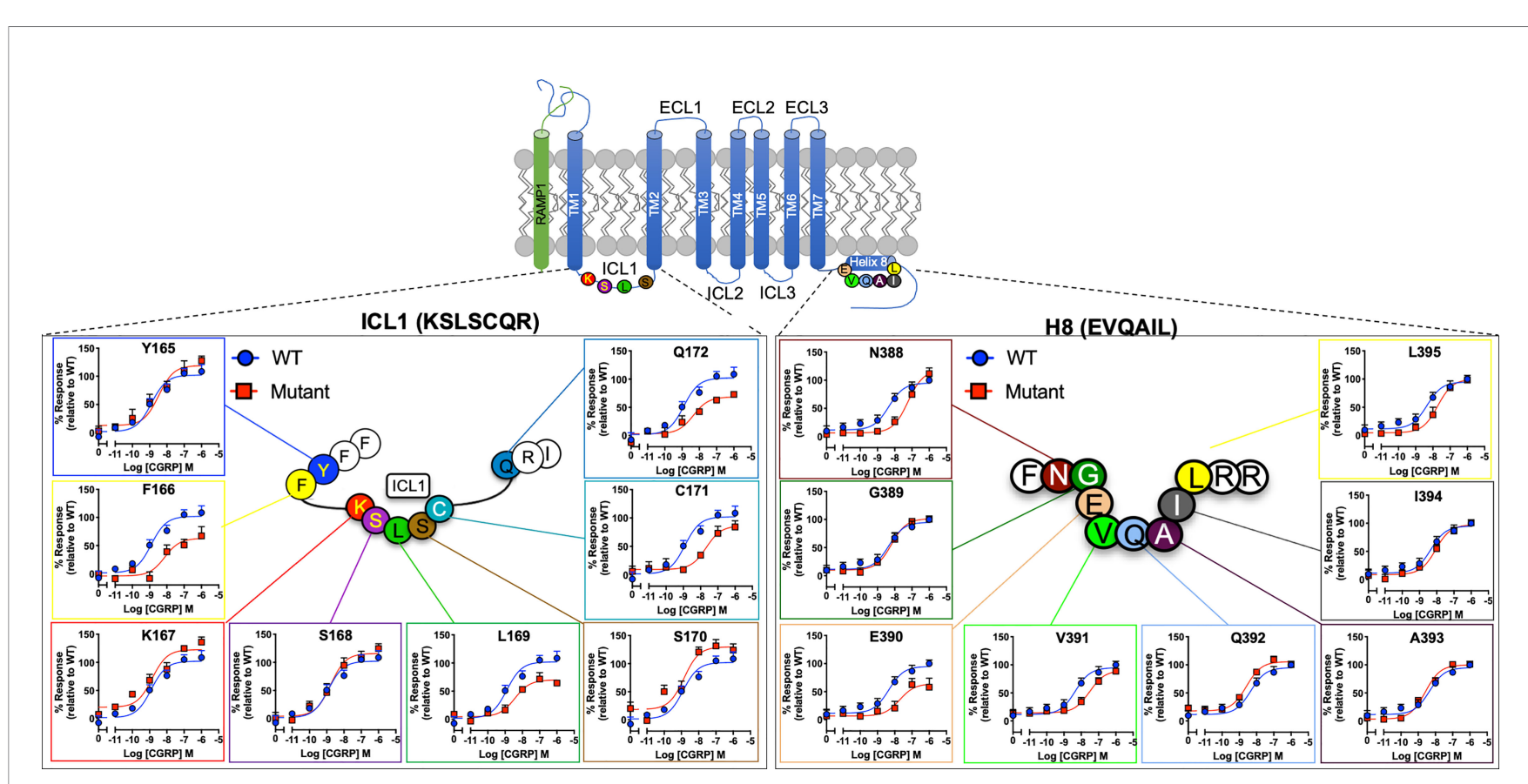

FIGURE 2 | Mutational analysis of residues in ICL1/H8 at the CGRP receptor. Residues in the ICL1 (left) and H8 (right) were mutated to Ala (except A393 where Leu was used) and the effects on cAMP production compared to wild type receptor. Mutant curves are show in red, wild type in blue. All data are mean \pm SEM of $n$ repeats where $n=$ minimum of 3 triplicates.

H8 differ depending on which coupling pathway is examined and ERK1/2 activation is much more sensitive to mutations in $\mathrm{H} 8$ than cAMP or ${ }_{\mathrm{i}} \mathrm{Ca}^{2+}$ elevation. These differences are highlighted in the bias plots for ICL1 and H8.

After preliminary experiments using saturation mutagenesis of ICL1 on CAMP production, the effect of glutamate, arginine, histidine, glycine and isoleucine were explored in detail, to examine the effect of charge and size at each position. This showed that substitutions at every position can alter receptor activation and/or receptor expression (Figure 5). Several interesting features appear from this extended data. Substitution by $\mathrm{R}$ within the motif is well tolerated apart from at L169; S168R increases CGRP potency by almost 100-fold and there was a small increase in Emax with Q172R. Substitution by $\mathrm{H}$ was best tolerated at $\mathrm{C} 171$ and replacement by $\mathrm{E}$ gives particularly large decreases in activity at every position apart from F165. Replacement of L169 by any residue apart from I reduces expression by at least $2 / 3$ compared to WT. Glycine substitution, generally deleterious, increases potency at L169 (albeit with a reduced $\mathrm{E}_{\max }$ ) and $\mathrm{C} 171$.

\section{Extension of Alanine Scan of ICL1 to the GCGR}

In the GCGR, the sequence of ICL1 is $\mathrm{G}^{165 / 1.61 \mathrm{~b}} \mathrm{~L}^{12.47 \mathrm{~b}}$ SKLHCTR and the corresponding $\mathrm{H} 8$ sequence is $\mathrm{NE}^{406 / 8.49 \mathrm{~b}} \mathrm{VQSEL}$ (underlined residues are the motifs, as shown for CLR in section 3.1 and 3.2). This is a more typical H8 sequence as $8.53 \mathrm{~b}$ is $\mathrm{E}$ in $12 / 15$ human class B GPCRs. To probe the differences/conservation of regions of activity, we focussed upon mutations of the ICL1 region of the GCGR. C171A failed to express and so was without activity in all signaling assays; K168A, L169A and H170A showed a 50\% reduction in expression. For the other mutants, cell-surface expression was not changed (Figure 6A). Alanine mutation of L169 $9^{12.50}$ and $\mathrm{T} 172^{12.52}$ reduced the extent of cAMP production; the other mutants that expressed were without effect on this pathway (Figure 6B). By contrast, both elevation of ${ }_{i} \mathrm{Ca}^{2++}$ mobilisation and (in contrast to the CLR) ERK1/2 signaling were far more sensitive to alanine substitution throughout ICL1 (Figures 6B-E and Table S6).

Immediately outside ICL1, R173 ${ }^{2.46 \mathrm{~b}} \mathrm{~A}$ reduced the potency of glucagon, almost 100-fold, on cAMP accumulation ( $\mathrm{pEC}_{50} \mathrm{WT}$, $\left.9.09 \pm 0.1 ; \mathrm{pEC}_{50} \mathrm{R} 173 \mathrm{~A}, 7.14 \pm 0.1, \mathrm{p}>0.01, \mathrm{n}=5\right)$. A limited characterisation of $\mathrm{H} 8$ was carried out, focussing on the two charged residues $\mathrm{E} 406^{8.49 \mathrm{~b}}$ and $\mathrm{E} 410^{8.543 \mathrm{~b}}$. The only effect on cAMP production was a very small increase in basal activity seen with E406A (WT $7.6 \pm 1.1 \%$ of response to forskolin, E406A, $11.1 \pm 1.5 \%, \mathrm{p}>0.05, \mathrm{n}=5)$. With the double mutant E406AE410A, the basal was further increased to $19.6 \pm 1.4 \%$ ( $\mathrm{p}>0.01$ ), again with no change in potency. However, for E406A, expression was $53.8 \pm 5.8 \%$ of WT and this was further reduced to $21.5 \pm 1.3 \%$ with E406AE410A, suggesting an increase in the effectiveness of coupling to Gs given the increase in basal and the maintenance of potency.

\section{ICL1 in the CRF-Type 1 Receptor (CRFR1)}

Our data suggested that ICL1 might have a role in determining $\mathrm{G}$ protein preference of Class B1 GPCRs. The CRFR1 exists in two 
A

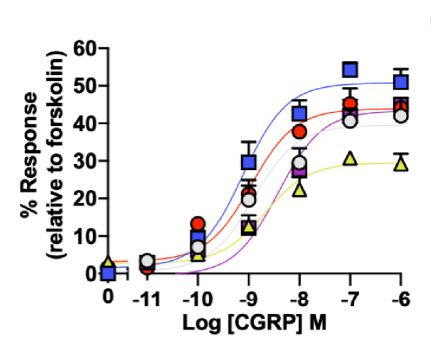

B

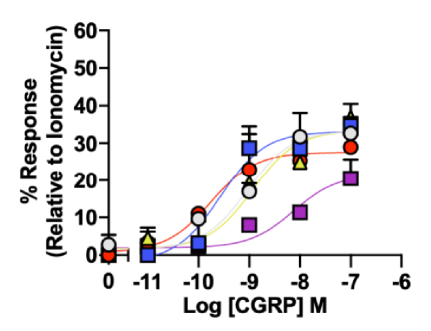

C

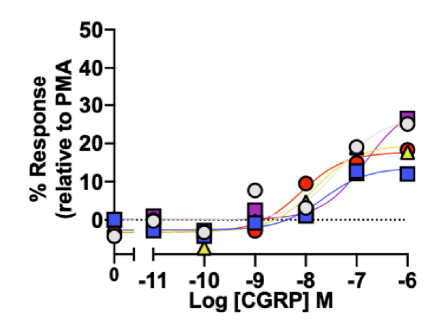

o wT

CAMP

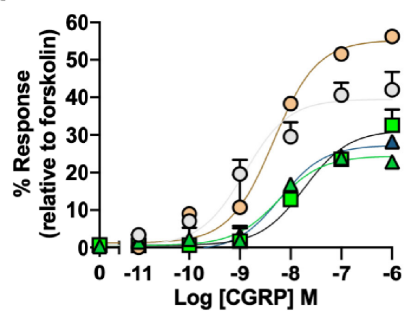

${ }_{i} \mathrm{Ca}^{2+}$

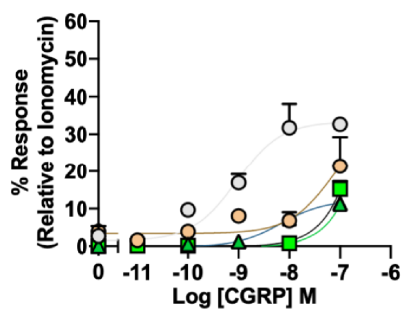

ERK1/2

FIGURE 3 | Signaling bias of alanine mutants of ICL1 at the CGRP receptor. Residues in the ICL1 were mutated to Ala (except A393 where Leu was used) and the effects on (A) cAMP production, (B) elevation of intracellular $\mathrm{Ca}^{2+}$, (C) pERK were compared to wild type receptor, (D) Signaling bias plot was calculated as $10^{\Delta \Delta(\tau /}$

KA) for each mutant and each signaling pathway relative to WT and ERK phosphorylation. Note I394A has not been included in the analysis due to a lack of signaling in the ${ }_{i} \mathrm{Ca}^{2+}$ and ERK1/2 assays. All data are mean \pm SEM of $n$ repeats where $n=$ minimum of 3 triplicates.

splice forms (1a and 1b) which differ due to the presence of a 29 amino acid insert in the RKLR motif which does not influence cell surface expression (49). Analysis of the signaling profiles suggests that the CRF1a receptor, which lacks the insert, is biased towards $\mathrm{Ca}^{2+}$ signaling, which is consistent with the motif being important for $\mathrm{G}$ protein specificity (Figure 7 and Table S7).

\section{Molecular Dynamics Simulation of ICL1 During Activation of the CGRP Receptor}

A comparison between the inactive and active CGRP and GluR structures (the latter in complex with both Gs and Gi) indicated that ICL1 only underwent subtle changes during the process of receptor activation. To further understand why mutations throughout this region can change activation, a molecular dynamic simulation was used to study the inactive-active transition in the CGRP receptor (Figure 8 and Videos S1A, B). Early during the simulation, the proximal region of ICL1 underwent a flexing movement centred on S168 ${ }^{12.49}$. This subtly changes the orientation of ICL1 with respect to both ICL2 and H8. This was followed by movements of ICL2. Around the middle of the simulation, N388.61b and E390 ${ }^{8.49}$ in ICL4 move towards L169 ${ }^{12.50}$. There is then a bending of the distal part of TM1 but ICL1 with H8 and ICL2 move largely as a rigid body as a consequence of this. At the very end of the simulation there are further movements of N388 and E390, coupled eventually to a change in the side-chain orientation of R173. At this stage, the G protein binding pocket is now fully open. The distance between L169 in ICL1 and E390 in H8 reflects these changes (Figure 8B). Broadly similar movements were seen during a molecular dynamics simulation of the glucagon receptor, with both early and late movements in ICL1 (Video S2).

\section{DISCUSSION}

The role of ICL1 in mediating signal transduction is poorly explored. In this paper, we confirm evidence (32) evidence for a 
A

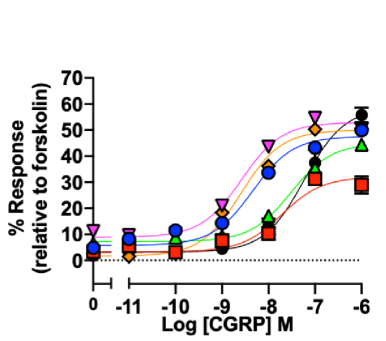

CAMP

B

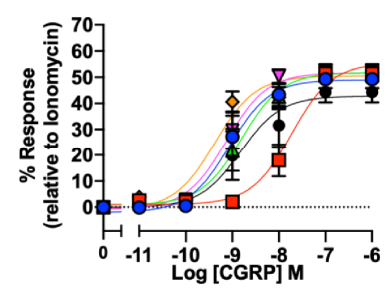

C

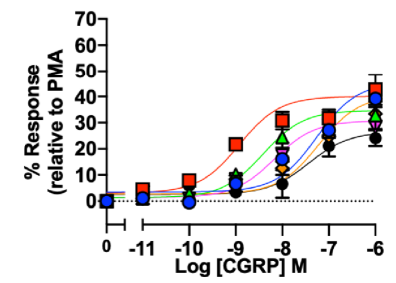

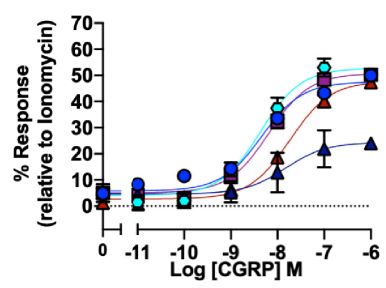

${ }_{i} \mathrm{Ca}^{2+}$

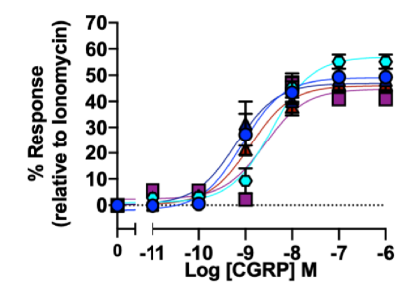

ERK1/2

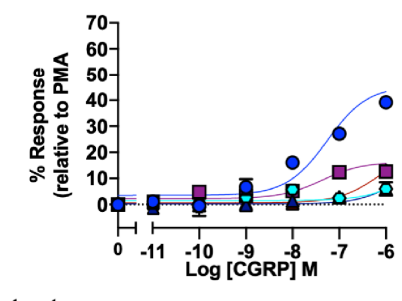

Mutants

$\bullet$ WT $\square$ E390A $\triangle$ V391A $\nabla$ Q392A $\diamond$ A393L $\bullet$ L395A 0 R396A $\Delta$ R397A $\square$ N398A $\Delta$ W399A

FIGURE 4 | Signaling bias of alanine mutants of H8 at the CGRP receptor. Residues in the H8 were mutated to Ala and the effects on (A) CAMP production, (B) elevation of ${ }_{i} \mathrm{Ca}^{2+}$, (C) ERK were compared to wild type receptor, (D) Signaling bias plot was calculated as $10^{\Lambda(\tau / K A)}$ for each mutant and each signaling pathway relative to WT and ERK $1 / 2$ phosphorylation. All data are mean \pm SEM of $n$ repeats where $n=$ minimum of 3 triplicates.

structural motif in the loop which is an important player in determining the specificity of $\mathrm{G}$ protein-coupling. It is possible to interpret some of the data using the current cryo-EM and crystal structures with further insight coming from molecular dynamics simulations. We have also used mutagenesis to explore the role of individual residues. Mutagenesis data needs to be interpreted with care as the mutants themselves can change the structure of a protein; however, it can be useful to explore interactions predicted from structural and modelling studies.

At first sight, the claim that ICL1 is important in modulating G protein signaling may seem surprising. The loop is usually short and could be considered simply as a linker between TMs 1 and 2. It makes no direct contact with the a subunits of $\mathrm{G}$ proteins. Furthermore, its conformation in G protein associated GPCRs is very similar to that of the apo-receptors. However, it has several interfaces in Class B1 GPCRs, as seen from structures (3-5, 8, 9, 5055) (Figure 9). The distal end of the loop faces towards TM3/4 and ICL2. It can indirectly influence ICL3 via changing the position of H8. In the inactive receptor, it can contact a string of bound water molecules that fit between TMs 2 and 7, at least in the high

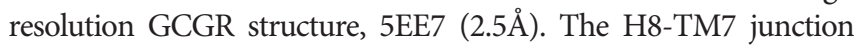

(ICL4) makes important contacts with the G protein when it binds to the receptor. ICL1 contacts the G $\beta$ subunit of the bound $G$ protein (Figure 9E) and $\mathrm{R}^{2.46 \mathrm{~b}}$ faces the Go subunit (Figures 9B, F). The contacts between ICL2 and, especially, ICL4 are of considerable potential significance as it is likely that these are key determinants of G protein selectivity $(2,56)$. ICL4 (between TM7 and H4) directly contacts the $\mathrm{H} 5$ helix of $\mathrm{G} \alpha$ subunits, which enters the cavity that opens on the cytosolic surface of GPCRs on agonist activation. ICL2 interacts with "rim" residues that flank H5 when it associates with GPCRs. The subtle changes observed in ICL4, depending on the nature of the interacting $G$ protein, are powerful drivers of $G$ protein association and specificity. In our molecular dynamics simulation of CLR, a very early event was a subtle movement of the proximal end of ICL1 followed by rearrangements of the TM2/ICL2 interface and then ICL4. We suggest that these underlie the actions of ICL1 in G protein-coupling. Some caution is needed in extrapolating between the molecular dynamics simulation as structural data suggests large scale movements of the cytoplasmic face of CLR require a $G$ protein to stabilise them (14); however, the simulations may have value in reflecting the conformational changes that are required for the $G$ protein interaction. 

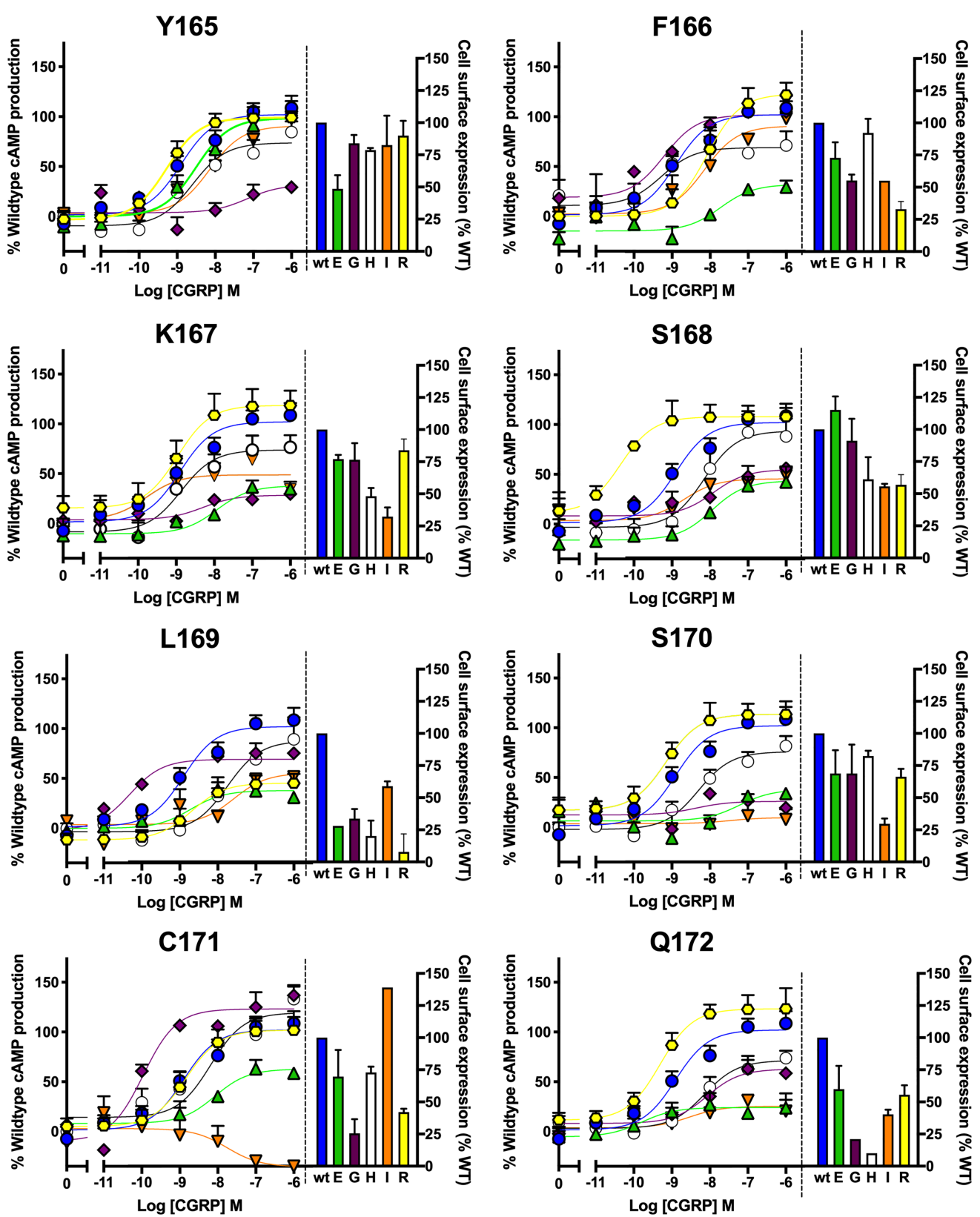

WT $\triangle E$

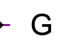

$-\mathrm{O}$

$\nabla \quad$ I

O R

FIGURE 5 | Mutagenic analysis of residues in ICL1 at the CGRP receptor. Residues in the ICL1 were mutated to a wide range of non-complementary amino acids (as indicated) and the effects on cAMP production compared to wild type receptor (concentration-response curves). Cell surface expression for each mutant was quantified and normalized to the wild type receptor. All data are mean \pm SEM of $n$ repeats where $n=$ minimum of 3 triplicates.

It is possible to suggest functions for some individual amino acids within ICL1. The majority of crystal structures show that the side chain of L169 ${ }^{12.50}$, (residue 169 in both CGRP and GCGR) in the middle of the loop points towards H8 (Figure 9). Thus $\mathrm{L}^{12.50}$ seems to be required to stabilise the $\mathrm{H} 8$ interaction, consistent with our observations that almost any mutation here reduces receptor expression. Residue 12.49 is usually basic and its sidechain points beneath the receptor; where a $G$ protein is present it interacts with D312 of G $\beta$ (Figures 9B, E). In the CGRP receptor, 12.49 is serine (perhaps connected to D312 and $\mathrm{H} 8$ by water molecules) and, interestingly, its mutation to arginine increases CGRP potency. This may work by 
A

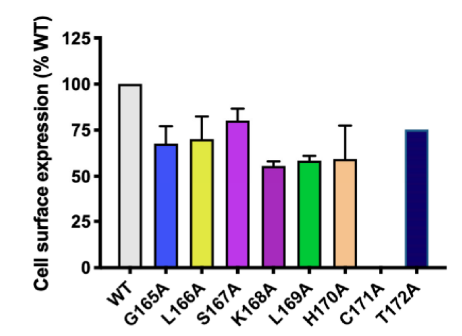

E

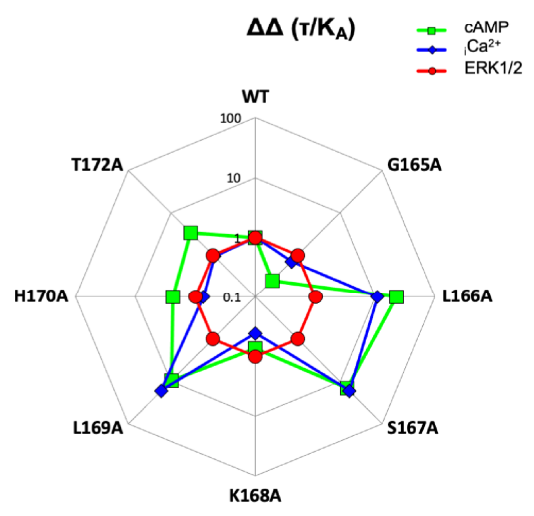

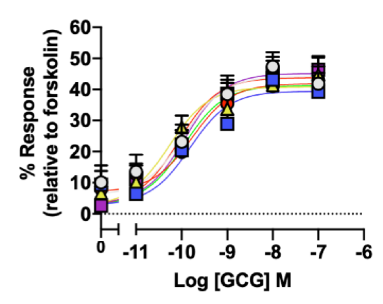

C

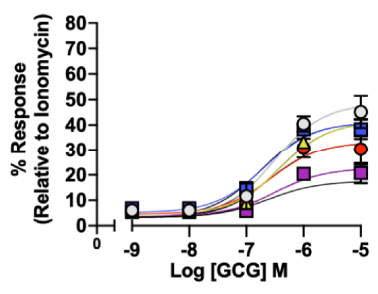

D

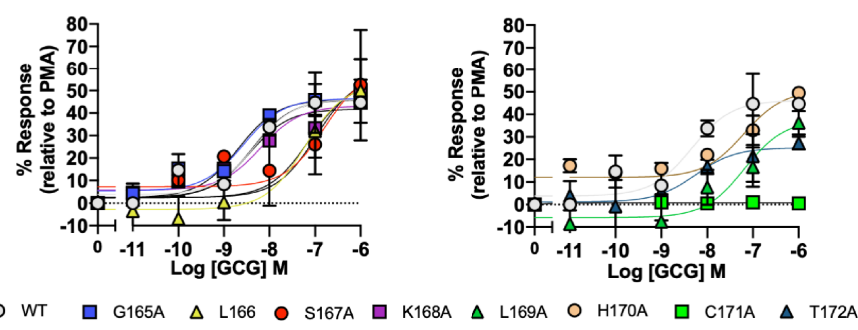

CAMP

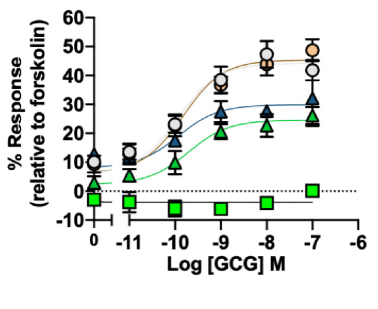

${ }_{i} \mathrm{Ca}^{2+}$

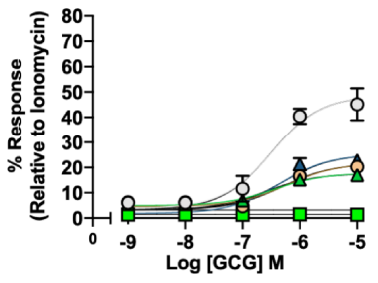

ERK1/2

FIGURE 6 | Signaling bias of alanine mutants of ICL1 at the Glucagon receptor. Residues in the ICL1 were mutated to Ala and the effects on (A) Cell surface expression, normalized to wild type GCGR, (B) CAMP production, (C) elevation of $\mathrm{Ca}^{2+}$, (D) ERK1/2 were compared to wild type receptor, (E) Signaling bias plot was calculated as $10^{\Delta \Delta(\tau / K A)}$ for each mutant and each signaling pathway relative to WT and ERK1/2 phosphorylation. All data are mean \pm SEM of $n$ repeats where $\mathrm{n}=$ minimum of 3 triplicates.

promoting $\mathrm{G}$ protein interaction. $\mathrm{K}^{12.48}$ of CLR also H-bonds to D52 and T50 of G $\beta$. In all class B1 GPCR structures, the absolutely conserved $\mathrm{C}^{2.44 \mathrm{~b}}$ faces towards $\mathrm{H} 8$ and $\mathrm{R}^{2.46 \mathrm{~b}}$, where its side chain is close to E8.49b, perhaps helping to stabilise the ionic interaction between the arginine and glutamic acid. The polarizability of the sulphur atom in cysteine may be significant here and explain the absolute conservation of the residue. There are also receptor-specific contacts for this residue. For the CGRP and active CRF1 receptors, its sidechain is orientated to Gos, although still close to $\mathrm{R}^{2.46 \mathrm{~b}}$. In the inactive GCCR (5EE7) and GLP-1R (5VEW), it also H-bonds to a water molecule in the cleft between H8 and ICL1. Alanine mutation of $\mathrm{C}^{2.44 \mathrm{~b}}$ in the PTH1 receptor results in loss of receptor expression (57), further suggestive of a role in all class B1 GPCRs. In the GCGR where the $2.45 \mathrm{~b}$ is the shorter threonine a bridging water molecule allows a hydrogen bond between the backbone amides of $2.45 \mathrm{~b}$, $2,46 \mathrm{~b}$ and the phenolic hydroxyl of Y248 ${ }^{3.53 b}$ (Figure 9H). In the CRF1R, L150 2.45b mediates hydrophobic interactions.

For all class B1 GPCRs, there are a complex set of interactions between the absolutely conserved $\mathrm{R}^{2.46 \mathrm{~b}}$ at the ICL1/TM2 junction and $\mathrm{E}^{8.49 \mathrm{~b}}$ and $\mathrm{N}^{7.61 \mathrm{~b}}$ at the H8/TM7 junction in the inactive receptors, probably involving water molecules (52) (Figures 9B, F). In the active receptors, these contacts undergo rearrangement to include Q390 and E392 at the C-terminus of H5 of Gos (Figure 8). This pattern of interaction is broadly similar in the PTH1, GLP-1, CGRP and calcitonin receptors $(6 \mathrm{NIY})(8,53,54)$, although the structures show differences in the orientation of the side chains.

Whilst it is possible explain some of the mutagenesis data in this study, it is hard to convincingly rationalise every result. Perhaps the most economical explanation is to suggest that mutations anywhere along ICL1 have the potential to change its conformation and so indirectly alter its interactions with ICL2 and ICL4. For this to be plausible, ICL1 must have a degree of flexibility. The molecular dynamics simulation suggests this is possible. However, the GPCR structures also speak to this issue. Perhaps not surprisingly, in the crystal structures ICL1 has a high B-factor, consistent with mobility. However, for the GCGR, two distinct conformations are seen, differing in their orientation of L169 ${ }^{12.50}$ (Figures 9D, E). For the CRFR1 structures, in the inactive $4 \mathrm{Z} 9 \mathrm{G}, \mathrm{H} 8$ cannot be resolved and the sidechain of $\mathrm{L}^{12.50}$ also points between TM1 and 2; it is in a 
A
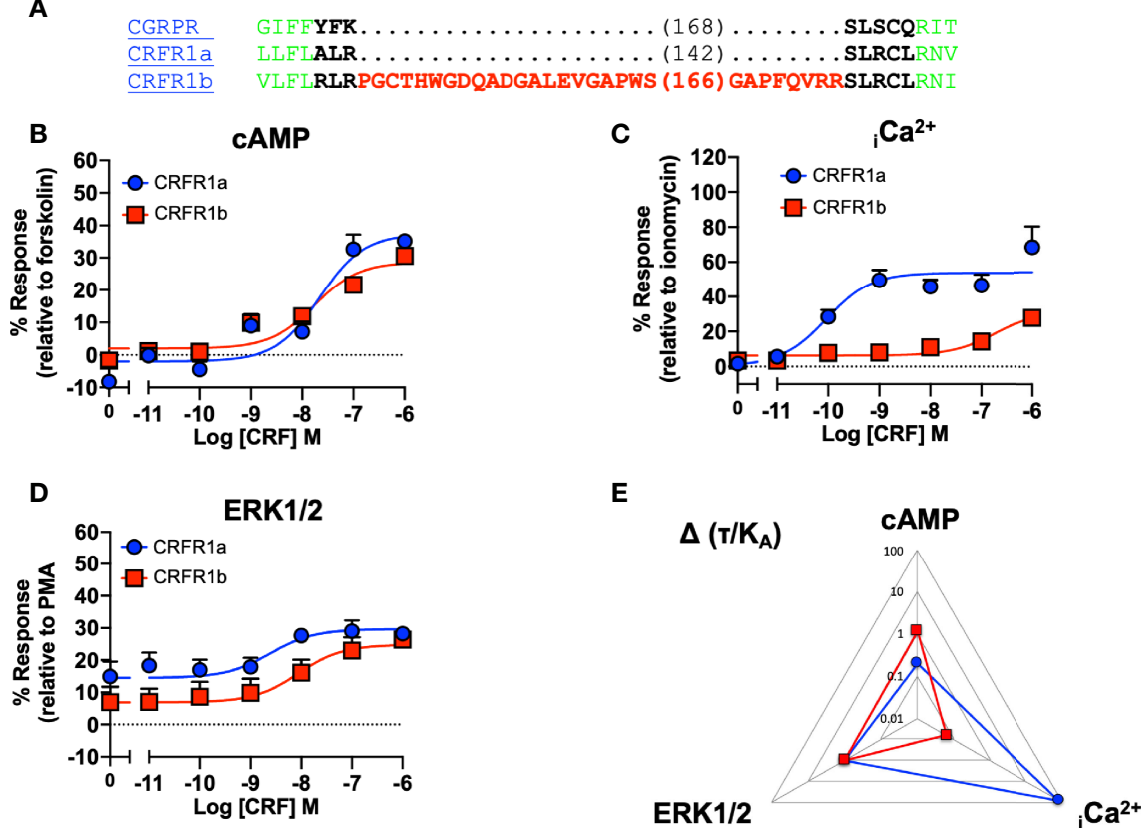

FIGURE 7 | Signaling bias of splice variants of ICL1 at the CRF receptor. (A) Sequence of CRFR1 splice variants, with CGRPR as reference. Splice variants of the CRFR1 were compared for (B) CAMP production, (C) elevation of ${ }_{i} \mathrm{Ca}^{2+}$, (D) ERK1/2 phosphorylation. (E) Signaling bias plot was calculated as $10^{\Delta(\tau / K A)}$ for each mutant and each signaling pathway relative to ERK1/2 phosphorylation. All data are mean \pm SEM of $n$ repeats where $n=$ minimum of 3 triplicates.

single turn of a helix at the proximal end of ICL1. However, in the active structures $(6 \mathrm{~PB} 0,6 \mathrm{P} 9 \mathrm{X})$, where $\mathrm{H} 8$ is seen, the helix is lost and $\mathrm{L}^{12.50}$ now faces H8. Thus, ICL1 is not rigid and

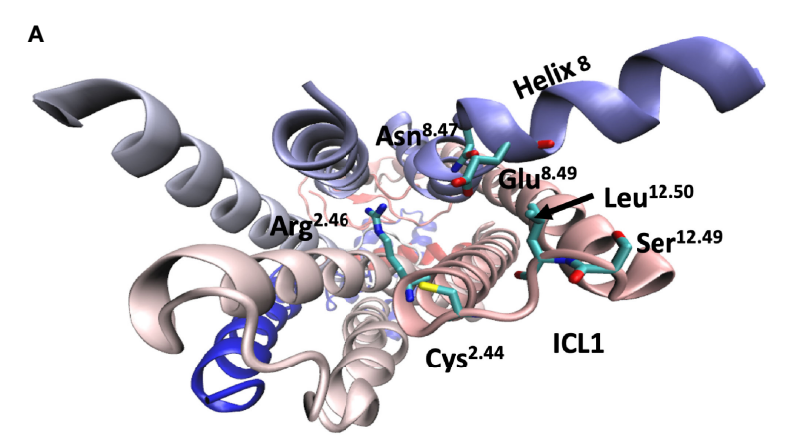

B

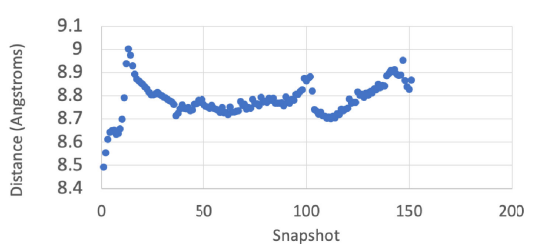

FIGURE 8 | Interactions of ICL1 during a molecular dynamics simulation of CLR. (A) Cytoplasmic view of CLR showing the main sidechains involved in interactions with ICL1. (B) Variation of the minimum distances between the centres of mass of L169-E390 during the molecular dynamics simulation. mutations could have unpredictable effects on its structure. Hydrogen-deuterium exchange has demonstrated that even in the absence of CGRP, ICL1 of CLR/RAMP1, with the other intracellular loops, has a high rate exchange, consistent with flexibility (14).

It is worth considering how $\mathrm{H} 8$ is adapted as a partner to ICL1. $\mathrm{E}^{8.49 \mathrm{~b}}$ of $\mathrm{H} 8$ faces centrally into ICL1 (Figures 9A-E); its presence may partially explain why the introduction of glutamate anywhere in ICL1 is deleterious as this is likely to result in ionic repulsion. The small increase in basal activity seen in the GCGR when it is substituted by alanine may be explained by the presence of an interaction between it and R346 at the base of TM6 seen in the inactive receptor (5EE7), which helps constrain the base of the receptor in a closed form. $\mathrm{E}^{8.49 \mathrm{~b}}$ is probably important in maintaining the orientation of $\mathrm{H} 8$ as it can interact directly or indirectly to $\mathrm{Q} / \mathrm{N}^{7.61 \mathrm{~b}}$ in both active and inactive receptors (Figures $\mathbf{9 A}, \mathbf{B}, \mathbf{D}, \mathbf{F}$ ), hence explaining why alanine mutagenesis reduces receptor expression. Apart from the junction with TM7, the rest of H8 appears to be of little importance for $G$ protein coupling but not for ERK1/2 activation. This presumably reflects the role that $\mathrm{H} 8$ plays in $\beta$ arrestin recruitment and subsequent ERK1/2 phosphorylation (58-61)

In the calcitonin and CRF1 receptors, splice variants exist in ICL1 (31). In this study, we show that the insertion changes receptor bias of the CRF1 receptor. For the calcitonin receptor there is reduced coupling to both cAMP and $\mathrm{Ca}^{2+}$ signaling, although it is not clear if there is any change in bias. It 
A

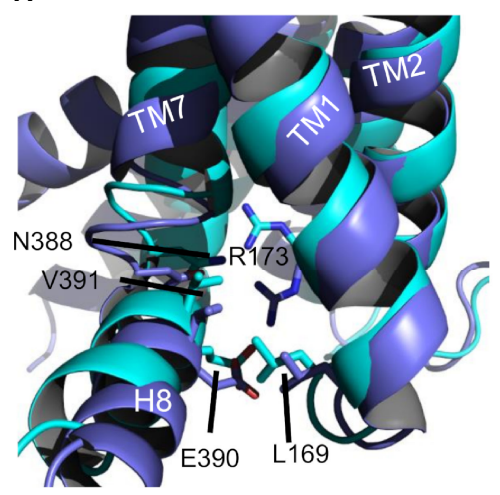

B

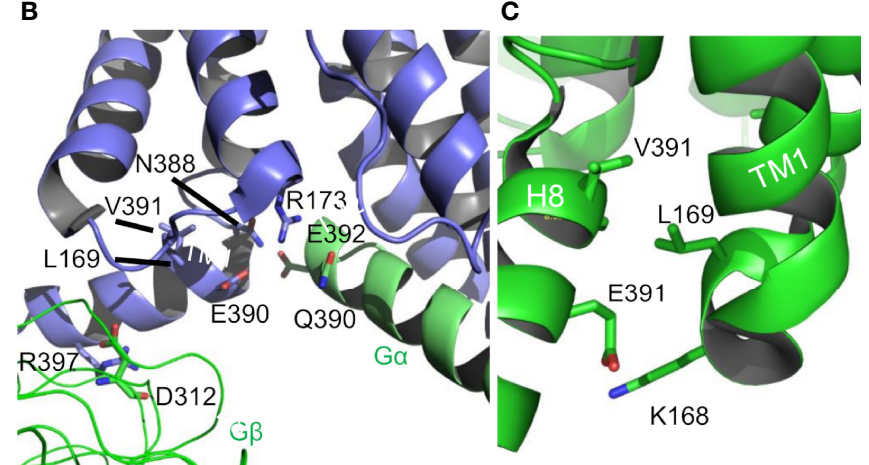

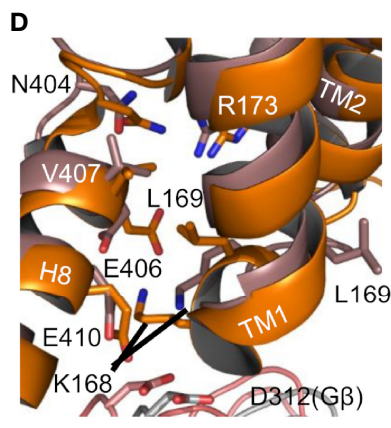

E
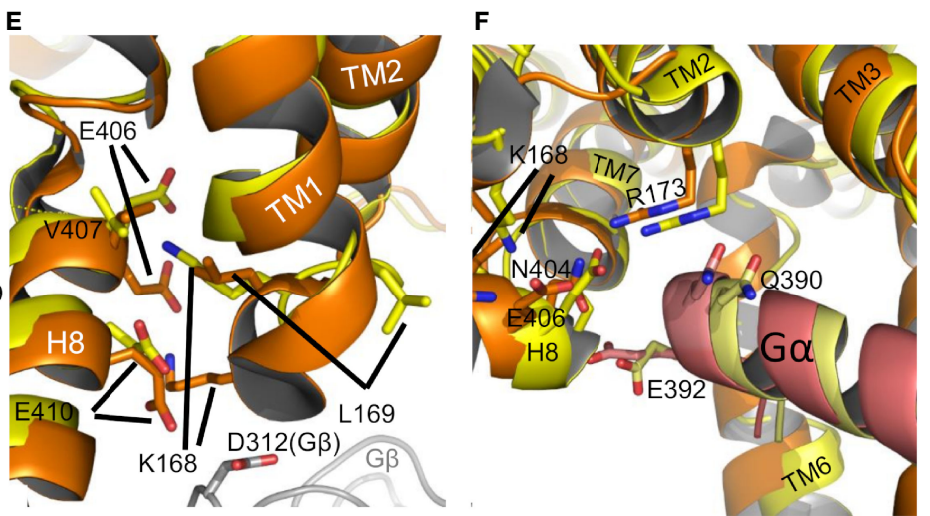

G

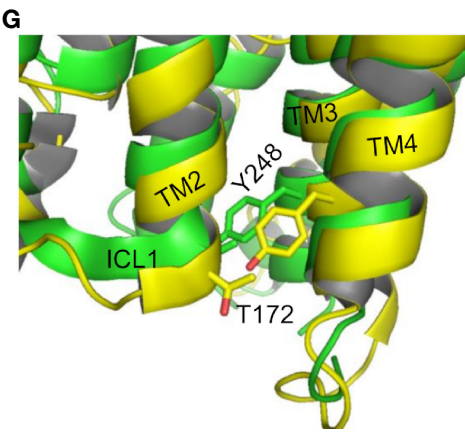

H
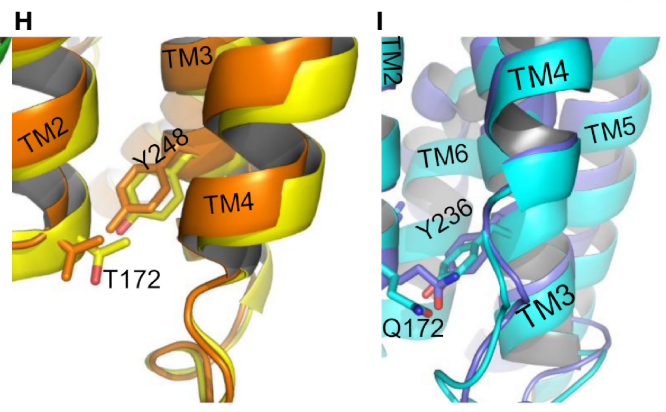

FIGURE 9 | The ICL1-H8 interface in CGRP. (A) The interface (6E3Y, active, slate; 7KNT inactive, cyan). (B) Contacts of the active CGRP (6E3Y, active, slate)

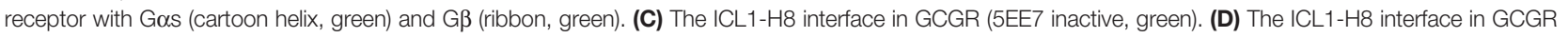
((6WPW active Gos, orange/6LML active Goi, brown)). In the inactive crystal structures 4L6R, 5YQZ, 5XEZ and the G protein bound cryo-em structures 6WHC, $6 L M K$, and $6 L M L$, there is a rotation in the middle of the ICL1 so that $\mathrm{L}^{12.50}$ points upwards between TM1 and TM2 and $\mathrm{K}^{12.49}$ points to $\mathrm{H} 8$. $\mathrm{E}^{8.49}$ and $\mathrm{E}^{8.53}$ can interact with the side chain of $\mathrm{K}^{12.49}$, perhaps helping to keep H8 engaged with ICL1. In the inverse-agonist stabilised crystal structure 5EEZ and the Gas-bound cryo-em 6WPW, $\mathrm{L}^{12.50}$ points to H8 and $\mathrm{K}^{12.49}$ is beneath the receptor. D312 of G $\beta$ is close to IL1 in both structures. (E) The ICL1-H8 interface in GCGR (6WPW active Gs, orange/6WHC active Gos, yellow). The variation of the K168 orientation is indicative of water mediated interactions. (F) Gos contacts in GCGR for 6WPW active, orange and 6WHC active, yellow. (G) The ICL1-ICL2 interface in the GCGR (5EE7 inactive). (H) The ICL1-ICL2 interface in the GCGR (6WPW active Gos, green/6WHC active Gi, orange). (I) The ICL1-ICL2 interface in the CGRP (6E3Y, active, cyan).

is not possible to provide any detailed mechanistic explanation with excessive speculation; however, it is significant that endogenous variants of ICL1 show differences in bias.

The equivalent of the RKLK motif can be recognized in class A GPCRs, where the ICL1 residues form a loosely conserved [R/ $\mathrm{H}]^{1.61} \mathrm{KL}[\mathrm{R} / \mathrm{H}]$ motif; the H8 motif is $\mathrm{E}^{8.49}$-FxxxF (Figure 1) (32). ICL1 has been identified as being important for constraining class B1 A and C GPCRs in inactive states (13), perhaps hinting at a wider role the motif may play. ICL1 is in close proximity to the binding sites for a number of allosteric antagonists that bind to the intracellular face of GPCRs $(50,62,63)$ and also the probable site of action of pepducins based on ICL1 sequences $(64,65)$. Given the number of interactions it can make, it may be a useful area for drug targeting.

In conclusion, ICL1 can influence the architecture of the G protein-binding pocket to favour either $G_{s}$ or $G_{q / 11}$ coupling, 
making this an important regulator of $G$ protein specificity. Residues at the distal end of the loop are particularly important and we suggest that they work largely by influencing the interplay between ICL4 and H5 of the G protein G $\alpha$ subunit.

\section{DATA AVAILABILITY STATEMENT}

The raw data supporting the conclusion of this article will be made available by the authors, on reasonable request.

\section{AUTHOR CONTRIBUTIONS}

IW, KB, SR, NJR, MH, and JS performed the experiments and modelling. CAR, AJ, DRP, and GL conceived the idea and analysed data. DRP, GL, and CAR wrote the manuscript.

\section{REFERENCES}

1. Katritch V, Cherezov V, Stevens RC. Structure-Function of the G ProteinCoupled Receptor Superfamily. Annu Rev Pharmacol Toxicol (2013) 53:53156. doi: 10.1146/annurev-pharmtox-032112-135923

2. Garcia-Nafria J, Tate CG. Cryo-EM Structures of GPCRs Coupled to Gs, Gi and Go. Mol Cell Endocrinol (2019) 488:1-13. doi: 10.1016/j.mce.2019.02.006

3. Ehrenmann J, Schoppe J, Klenk C, Rappas M, Kummer L, Dore AS, et al. High-Resolution Crystal Structure of Parathyroid Hormone 1 Receptor in Complex With a Peptide Agonist. Nat Struct Mol Biol (2018) 25:1086-92. doi: 10.1038/s41594-018-0151-4

4. Hollenstein K, Kean J, Bortolato A, Cheng RK, Dore AS, Jazayeri A, et al. Structure of Class B GPCR Corticotropin-Releasing Factor Receptor 1. Nature (2013) 499:438-43. doi: 10.1038/nature12357

5. Jazayeri A, Rappas M, Brown AJH, Kean J, Errey JC, Robertson NJ, et al. Crystal Structure of the GLP-1 Receptor Bound to a Peptide Agonist. Nature (2017) 546:254-8. doi: 10.1038/nature22800

6. Karageorgos V, Venihaki M, Sakellaris S, Pardalos M, Kontakis G, Matsoukas MT, et al. Current Understanding of the Structure and Function of Family B GPCRs to Design Novel Drugs. Hormones (Athens) (2018) 17:45-59. doi: 10.1007/s42000-018-0009-5

7. Liang YL, Khoshouei M, Radjainia M, Zhang Y, Glukhova A, Tarrasch J, et al. Phase-Plate Cryo-EM Structure of a Class B GPCR-G-Protein Complex. Nature (2017) 546:118-23. doi: 10.1038/nature22327

8. Liang YL, Khoshouei M, Glukhova A, Furness SGB, Zhao P, Clydesdale L, et al. Phase-Plate Cryo-EM Structure of a Biased Agonist-Bound Human GLP-1 Receptor-Gs Complex. Nature (2018) 555:121-5. doi: 10.1038/ nature25773

9. Liang YL, Khoshouei M, Deganutti G, Glukhova A, Koole C, Peat TS, et al. Cryo-EM Structure of the Active, Gs-Protein Complexed, Human CGRP Receptor. Nature (2018) 561:492-7. doi: 10.1038/s41586-018-0535-y

10. Wootten D, Christopoulos A, Marti-Solano M, Babu MM, Sexton PM. Mechanisms of Signalling and Biased Agonism in G Protein-Coupled Receptors. Nat Rev Mol Cell Biol (2018) 19:638-53. doi: 10.1038/s41580-018-0049-3

11. Thal DM, Vuckovic Z, Draper-Joyce CJ, Liang YL, Glukhova A, Christopoulos A, et al. Recent Advances in the Determination of G Protein-Coupled Receptor Structures. Curr Opin Struct Biol (2018) 51:28-34. doi: 10.1016/ j.sbi.2018.03.002

12. Gurevich VV, Gurevich EV. The Structural Basis of the Arrestin Binding to GPCRs. Mol Cell Endocrinol (2019) 484:34-41. doi: 10.1016/j.mce.2019.01.019

13. Hauser AS, Kooistra AJ, Munk C, Heydenreich FM, Veprintsev DB, Bouvier M, et al. GPCR Activation Mechanisms Across Classes and Macro/Microscale. Nat Struc Mol Biol (2021) 28:879-88. doi: 10.1038/s41594-021-00674-7
All authors provided edits and comments. All authors contributed to the article and approved the submitted version.

\section{FUNDING}

This work was supported by the following BBSRC grants (BB/ $\mathrm{M} 00015 \mathrm{X} / 1$ (to GL), BB/M000176/1 (to DRP), and BB/ M006883/1 (to C.A.R.), MRC Doctoral Training Partnership MR/J003964/1 (to IW), the BBSRC-funded Midlands Integrative Biosciences Training Partnership (MIBTP) (KB).

\section{SUPPLEMENTARY MATERIAL}

The Supplementary Material for this article can be found online at: https://www.frontiersin.org/articles/10.3389/fendo.2021.792912/ full\#supplementary-material

14. Josephs TM, Belousoff MJ, Liang YL, Piper SJ, Cao J, Garama DJ, et al. Structure and Dynamics of the CGRP Receptor in Apo and Peptide-Bound Forms. Science (2021) 372(6538):eabf7258. doi: 10.1126/science.abf7258

15. Wang X, Cheng X, Zhao L, Wang Y, Ye C, Zou X, et al. Molecular Insights Into Differentiated Ligand Recognition of the Human Parathyroid Hormone Receptor 2. Proc Natl Acad Sci U S A (2021) 118:e2101279118. doi: 10.1073/ pnas. 2101279118

16. Bentrop J, Schwab K, Pak WL, Paulsen R. Site-Directed Mutagenesis of Highly Conserved Amino Acids in the First Cytoplasmic Loop of Drosophila Rh1 Opsin Blocks Rhodopsin Synthesis in the Nascent State. EMBO J (1997) 16:1600-9. doi: 10.1093/emboj/16.7.1600

17. Wess J. Molecular Basis of Receptor/G-Protein-Coupling Selectivity. Pharmacol Ther (1998) 80:231-64. doi: 10.1016/S0163-7258(98)00030-8

18. Amatruda TT3rd, Dragas-Graonic S, Holmes R, Perez HD. Signal Transduction by the Formyl Peptide Receptor. Studies Using Chimeric Receptors and Site-Directed Mutagenesis Define a Novel Domain for Interaction With G-Proteins. J Biol Chem (1995) 270:28010-3. doi: $10.1074 /$ jbc. 270.47 .28010

19. Hirata T, Kakizuka A, Ushikubi F, Fuse I, Okuma M, Narumiya S. Arg60 to Leu Mutation of the Human Thromboxane A2 Receptor in a Dominantly Inherited Bleeding Disorder. J Clin Invest (1994) 94:1662-7. doi: 10.1172/ JCI117510

20. Kleinau G, Jaeschke H, Worth CL, Mueller S, Gonzalez J, Paschke R, et al. Principles and Determinants of G-Protein Coupling by the Rhodopsin-Like Thyrotropin Receptor. PloS One (2010) 5:e9745. doi: 10.1371/ journal.pone.0009745

21. Liu B, Wu D. The First Inner Loop of Endothelin Receptor Type B is Necessary for Specific Coupling to Galpha 13. J Biol Chem (2003) 278:2384-7. doi: 10.1074/jbc.M208683200

22. Mathi SK, Chan Y, Li X, Wheeler MB. Scanning of the Glucagon-Like Peptide-1 Receptor Localizes G Protein-Activating Determinants Primarily to the N Terminus of the Third Intracellular Loop. Mol Endocrinol (1997) 11:424-32. doi: 10.1210/mend.11.4.9913

23. Wu V, Yang M, McRoberts JA, Ren J, Seensalu R, Zeng N, et al. First Intracellular Loop of the Human Cholecystokinin-A Receptor is Essential for Cyclic AMP Signaling in Transfected HEK-293 Cells. J Biol Chem (1997) 272:9037-42. doi: 10.1074/jbc.272.14.9037

24. Yu J, Polgar P, Lubinsky D, Gupta M, Wang L, Mierke D, et al. Coulombic and Hydrophobic Interactions in the First Intracellular Loop Are Vital for Bradykinin B2 Receptor Ligand Binding and Consequent Signal Transduction. Biochemistry (2005) 44:5295-306. doi: 10.1021/bi048288i

25. Zhang B, Yang X, Tiberi M. Functional Importance of Two Conserved Residues in Intracellular Loop 1 and Transmembrane Region 2 of Family A 
GPCRs: Insights From Ligand Binding and Signal Transduction Responses of D1 and D5 Dopaminergic Receptor Mutants. Cell Signal (2015) 27:2014-25. doi: 10.1016/j.cellsig.2015.07.006

26. Kuwasako K, Kitamura K, Nagata S, Hikosaka T, Kato J. Structure-Function Analysis of Helix 8 of Human Calcitonin Receptor-Like Receptor Within the Adrenomedullin 1 Receptor. Peptides (2011) 32:144-9. doi: 10.1016/ j.peptides.2010.10.005

27. West GM, Chien EY, Katritch V, Gatchalian J, Chalmers MJ, Stevens RC, et al. Ligand-Dependent Perturbation of the Conformational Ensemble for the GPCR Beta2 Adrenergic Receptor Revealed by HDX. Structure (2011) 19:1424-32. doi: 10.1016/j.str.2011.08.001

28. Sounier R, Mas C, Steyaert J, Laeremans T, Manglik A, Huang W, et al. Propagation of Conformational Changes During Mu-Opioid Receptor Activation. Nature (2015) 524:375-8. doi: 10.1038/nature14680

29. Koehl A, Hu H, Maeda S, Zhang Y, Qu Q, Paggi JM, et al. Structure of the Micro-Opioid Receptor-Gi Protein Complex. Nature (2018) 558:547-52. doi: 10.1038/s41586-018-0219-7

30. Shihoya W, Nishizawa T, Okuta A, Tani K, Dohmae N, Fujiyoshi Y, et al. Activation Mechanism of Endothelin ETB Receptor by Endothelin-1. Nature (2016) 537:363-8. doi: 10.1038/nature19319

31. Furness SG, Wootten D, Christopoulos A, Sexton PM. Consequences of Splice Variation on Secretin Family G Protein-Coupled Receptor Function. $\mathrm{Br} \mathrm{J}$ Pharmacol (2012) 166:98-109. doi: 10.1111/j.1476-5381.2011.01571.x

32. Vohra S, Taddese B, Conner AC, Poyner DR, Hay DL, Barwell J, et al. Similarity Between Class A and Class B G-Protein-Coupled Receptors Exemplified Through Calcitonin Gene-Related Peptide Receptor Modelling and Mutagenesis Studies. J R Society Interface / R Soc (2013) 10:20120846. doi: 10.1098/rsif.2012.0846

33. Weston C, Winfield I, Harris M, Hodgson R, Shah A, Dowell SJ, et al. Receptor Activity-Modifying Protein-Directed G Protein Signaling Specificity for the Calcitonin Gene-Related Peptide Family of Receptors. J Biol Chem (2016) 291:21925-44. doi: 10.1074/jbc.M116.751362

34. Clark AJ, Mullooly N, Safitri D, Harris M, de Vries T, MaassenVanDenBrink A, et al. CGRP, Adrenomedullin and Adrenomedullin 2 Display Endogenous GPCR Agonist Bias in Primary Human Cardiovascular Cells. Commun Biol (2021) 41:776. doi: 10.1038/s42003-021-02293-w

35. Hay DL, Garelja ML, Poyner DR, Walker CS. Update on the Pharmacology of Calcitonin/CGRP Family of Peptides: IUPHAR Review 25. Br J Pharmacol (2018) 175:3-17. doi: 10.1111/bph.14075

36. Marti-Solano M, Crilly SE, Malinverni D, Munk C, Harris M, Pearce A, et al. Combinatorial Expression of GPCR Isoforms Affects Signalling and Drug Responses. Nature (2020) 587:650-6. doi: 10.1038/s41586-020-2888-2

37. Knight A, Hemmings JL, Winfield I, Leuenberger M, Frattini E, Frenguelli BG, et al. Discovery of Novel Adenosine Receptor Agonists That Exhibit Subtype Selectivity. J Med Chem (2016) 59:947-64. doi: 10.1021/acs.jmedchem.5b01402

38. Sali A, Blundell TL. Comparative Protein Modelling by Satisfaction of Spatial Restraints. J Mol Biol (1993) 234:779-815. doi: 10.1006/jmbi.1993.1626

39. Barth P, Schonbrun J, Baker D. Toward High-Resolution Prediction and Design of Transmembrane Helical Protein Structures. Proc Natl Acad Sci USA (2007) 104:15682-7. doi: 10.1073/pnas.0702515104

40. Linder T, de Groot BL, Stary-Weinzinger A. Probing the Energy Landscape of Activation Gating of the Bacterial Potassium Channel KcsA. PloS Comput Biol (2013) 9:e1003058. doi: 10.1371/journal.pcbi.1003058

41. Bas DC, Rogers DM, Jensen JH. Very Fast Prediction and Rationalization of pKa Values for Protein-Ligand Complexes. Proteins (2008) 73:765-83. doi: $10.1002 /$ prot.22102

42. Van Der Spoel D, Lindahl E, Hess G, Groenhof G, Mark AE, Berendsen HJ. GROMACS: Fast, Flexible, and Free. J Comput Chem (2005) 26:1701-18. doi: $10.1002 /$ jcc. 20291

43. Kooistra AJ, Mordalski S, Pándy-Szekeres G, Esguerra M, Mamyrbekov A, Munk C, et al. GPCRdb in 2021: Integrating GPCR Sequences, Structures and Functions. Nucl Acids Res (2021) 49:D335-43. doi: 10.1093/nar/gkaa1080

44. Black JW, Leff P. Operational Models of Pharmacological Agonism. Proc R Soc London Ser B (1983) 220:141- 162. doi: 10.1098/rspb.1983.0093

45. Ballesteros JA, Weinstein H. Integrated Methods for the Construction of Three-Dimensional Models and Computational Probing of StructureFunction Relations in G Protein-Coupled Receptors. Meth Neurosci (1995) 25:366-428. doi: 10.1016/S1043-9471(05)80049-7
46. Wootten D, Simms J, Miller LJ, Christopoulos A, Sexton PM. Polar Transmembrane Interactions Drive Formation of Ligand-Specific and Signal Pathway-Biased Family B G Protein-Coupled Receptor Conformations. Proc Natl Acad Sci U.S.A. (2013) 110:5211-6. doi: 10.1073/pnas.1221585110

47. Barwell J, Conner A, Poyner DR. Extracellular Loops 1 and 3 and Their Associated Transmembrane Regions of the Calcitonin Receptor-Like Receptor Are Needed for CGRP Receptor Function. Biochim Biophys Acta (2011) 1813:1906-16. doi: 10.1016/j.bbamcr.2011.06.005

48. Walker CS, Conner AC, Poyner DR, Hay DL. Regulation of Signal Transduction by Calcitonin Gene-Related Peptide Receptors. Trends Pharmacol Sci (2010) 31:476-48. doi: 10.1016/j.tips.2010.06.006

49. Hauger RL, Grigoriadis DE, Dallman MF, Plotsky PM, Vale WW, Dautzenberg FM, et al. Current Status of the Nomenclature for Receptors for Corticotropin-Releasing Factor and Their Ligands. Pharmacol Rev (2003) 55:21-6. doi: 10.1124/pr.55.1.3

50. Jazayeri A, Dore AS, Lamb D, Krishnamurthy H, Southall SM, Baig AH, et al. Extra-Helical Binding Site of a Glucagon Receptor Antagonist. Nature (2016) 533:274-7. doi: 10.1038/nature17414

51. Siu FY, He M, de Graaf C, Han GW, Yang D, Zhang Z, et al. Structure of the Human Glucagon Class B G-Protein-Coupled Receptor. Nature (2013) 499:444-9. doi: 10.1038/nature12393

52. Song G, Yang D, Wang Y, de Graaf C, Zhou Q, Jiang S, et al. Human GLP-1 Receptor Transmembrane Domain Structure in Complex With Allosteric Modulators. Nature (2017) 546:312-5. doi: 10.1038/nature22378

53. Zhang H, Qiao A, Yang D, Yang L, Dai A, de Graaf C, et al. Structure of the Full-Length Glucagon Class B G-Protein-Coupled Receptor. Nature (2017) 546:259-64. doi: 10.1038/nature22363

54. Zhang Y, Sun B, Feng D, Hu H, Chu M, Qu Q, et al. Cryo-EM Structure of the Activated GLP-1 Receptor in Complex With a G Protein. Nature (2017) 546:248-53. doi: 10.1038/nature22394

55. Zhang H, Qiao A, Yang L, Van Eps N, Frederiksen KS, Yang D, et al. Structure of the Glucagon Receptor in Complex With a Glucagon Analogue. Nature (2018) 553:106-10. doi: 10.1038/nature25153

56. Inoue A, Raimondi F, Kadji F, Singh G, Kishi T, Uwamizu A, et al. Illuminating G-Protein-Coupling Selectivity of GPCRs. Cell (2019) 177:1933-47. doi: 10.1016/j.cell.2019.04.044

57. Thomas BE, Wittelsberger A, Woznica I, Hsieh MY, Monaghan P, Lee BK, et al. Cysteine at Position 217 in the Intracellular Loop 1 Plays a Critical Role in Human PTH Receptor Type 1 Membrane Translocation and Function. J Bone Miner Res (2007) 22:609-16. doi: 10.1359/jbmr.070101

58. Kisselev OG, McDowell JH, Hargrave PA. The Arrestin-Bound Conformation and Dynamics of the Phosphorylated Carboxy-Terminal Region of Rhodopsin. FEBS Lett (2004) 564:307-11. doi: 10.1016/S0014-5793(04) 00226-1

59. He QT, Xiao P, Huang SM, Jia YL, Zhu ZL, Lin JY, et al. Structural Studies of Phosphorylation-Dependent Interactions Between the V2R Receptor and Arrestin-2. Nat Commun (2021) 22:2396. doi: 10.1038/s41467-021-22731-x

60. Nguyen AH, Thomsen ARB, Cahill TJ3rd, Huang R, Huang LY, Marcink T, et al. Structure of an Endosomal Signaling GPCR-G Protein- $\beta$-Arrestin Megacomplex. Nat Struct Mol Biol (2019) 26:1123-31. doi: 10.1038/s41594019-0330-y

61. Min K, Yoon HJ, Park JY, Baidya M, Dwivedi-Agnihotri H, Maharana J, et al. Crystal Structure of $\beta$-Arrestin 2 in Complex With CXCR7 Phosphopeptide. Structure (2020) 28:1014-1023.e4. doi: 10.1016/j.str.2020.06.002

62. Liu X, Ahn S, Kahsai AW, Meng KC, Latorraca NR, Pani B, et al. Mechanism of Intracellular Allosteric Beta2ar Antagonist Revealed by X-Ray Crystal Structure. Nature (2017) 548:480-4. doi: 10.1038/nature23652

63. Wold EA, Chen J, Cunningham KA, Zhou J. Allosteric Modulation of Class A GPCRs: Targets, Agents, and Emerging Concepts. J Med Chem (2019) 62:88127. doi: $10.1021 /$ acs.jmedchem. 8 b00875

64. O'Callaghan K, Kuliopulos A, Covic L. Turning Receptors on and Off With Intracellular Pepducins: New Insights Into G-Protein-Coupled Receptor Drug Development. J Biol Chem (2012) 287:12787-96. doi: 10.1074/ jbc.R112.355461

65. Grisanti LA, Thomas TP, Carter RL, de Lucia C, Gao E, Koch WJ, et al. Pepducin-Mediated Cardioprotection via Beta-Arrestin-Biased Beta2Adrenergic Receptor-Specific Signaling. Theranostics (2018) 8:4664-78. doi: 10.7150/thno.26619 
Conflict of Interest: AJ and NJR were employees of Sosei Heptares at the time the work was performed. Neither are now employed by Sosei Heptares.

The remaining authors declare that the research was conducted in the absence of any commercial or financial relationships that could be construed as a potential conflict of interest.

Publisher's Note: All claims expressed in this article are solely those of the authors and do not necessarily represent those of their affiliated organizations, or those of the publisher, the editors and the reviewers. Any product that may be evaluated in this article, or claim that may be made by its manufacturer, is not guaranteed or endorsed by the publisher.

Copyright $\odot 2022$ Winfield, Barkan, Routledge, Robertson, Harris, Jazayeri, Simms, Reynolds, Poyner and Ladds. This is an open-access article distributed under the terms of the Creative Commons Attribution License (CC BY). The use, distribution or reproduction in other forums is permitted, provided the original author(s) and the copyright owner(s) are credited and that the original publication in this journal is cited, in accordance with accepted academic practice. No use, distribution or reproduction is permitted which does not comply with these terms. 